\title{
Telavancin in Hospital-Acquired and Ventilator- Associated Pneumonia (HAP/VAP) Caused by Staphylococcus aureus: Post Hoc Analysis of 2 Randomized, Controlled Trials
}

\author{
Michael S. Niederman - Patrick C. Lee - Steven L. Barriere \\ Chris N. Barnes · Bibiana Castaneda-Ruiz
}

Received: April 18, 2019 / Published online: August 1, 2019

(C) The Author(s) 2019

\begin{abstract}
Introduction: The efficacy and safety of telavancin versus vancomycin in microbiologically evaluable patients with hospital-acquired or ventilator-associated pneumonia (HAP/VAP) caused by Staphylococcus aureus with vancomycin minimum inhibitory concentration (MIC) $\geq 1.0 \mu \mathrm{g} / \mathrm{mL}$ was analyzed using data derived from previously reported Assessment of Telavancin for Treatment of Hospital-Acquired Pneumonia (ATTAIN) trials.

Methods: This post hoc subgroup analysis of two randomized, double-blind, comparatorcontrolled, parallel-group phase 3 trials conducted at 274 sites in 38 countries included 194 microbiologically evaluable patients with HAP/
\end{abstract}

Enhanced Digital Features To view enhanced digital features for this article go to https://doi.org/10.6084/ m9.figshare. 8889845 .

M. S. Niederman

Division of Pulmonary and Critical Care Medicine, Weill Cornell Medicine, New York, NY, USA

P. C. Lee

Department of Surgery, Baystate Medical Center, Springfield, MA, USA

S. L. Barriere - C. N. Barnes $(\bowtie) \cdot$ B. Castaneda-Ruiz Theravance Biopharma US, Inc., South San Francisco, CA, USA

e-mail: cbarnes@sprucebiosicences.com
VAP caused by monomicrobial $S$. aureus with vancomycin MIC $\geq 1.0 \mu \mathrm{g} / \mathrm{mL}$. Patients received intravenous telavancin $(10 \mathrm{mg} / \mathrm{kg}$ every $24 \mathrm{~h}$ ) or intravenous vancomycin (1 g every $12 \mathrm{~h}$ with site-specific modifications) for 7-21 days. Efficacy was assessed by clinical cure, defined as improvement or non-progression of radiographic findings at end of treatment and resolution of pneumonia signs and symptoms at follow-up/test-of-cure visits, and survival 28 days post-randomization. Safety was assessed from categorical shifts in creatinine clearance during therapy and adverse events (AEs).

Results: Clinical cure rates were numerically greater following telavancin versus vancomycin treatment overall $(85.4 \%$ vs. $74.3 \%$; treatment difference [95\% confidence interval (CI)], 11.1\% $[-0.002 \%, 22.2 \%])$ and in patients aged $\geq 65$ years $(81.6 \%$ vs. $66.2 \%$; treatment difference [95\% CI], $15.5 \%$ [- 0.9\%, 30.2\%]) patients with VAP $(92.3 \%$ vs. $47.6 \%$; treatment difference [95\% CI], 44.7\% [18.1\%, 64.9\%]), and patients with baseline Acute Physiology And Chronic Health Evaluation II score $\geq 20$ (71.4\% vs. $55.6 \%$; treatment difference [95\% CI], $15.9 \%$ [- 11.7\%, 40.5\%]). Renal function declined in 7 (7.9\%) patients receiving telavancin and 6 (5.7\%) patients receiving vancomycin. Survival proportion was numerically higher $(85.2 \%$ vs. $80.2 \%$; treatment difference [95\% CI], 5.0\% $[-5.8 \%, 15.8 \%])$ and AEs were comparable in patients treated with telavancin versus vancomycin. 
Conclusion: Telavancin is an alternative to vancomycin for HAP/VAP caused by $S$. aureus with vancomycin $\mathrm{MIC} \geq 1 \mu \mathrm{g} / \mathrm{mL}$.

Funding: Theravance Biopharma R\&D, Inc., South San Francisco, CA, USA.

Keywords: Hospital-acquired pneumonia; MRSA; Staphylococcus aureus; Telavancin; Vancomycin; Ventilator-associated pneumonia

\section{INTRODUCTION}

Hospital-acquired pneumonia and ventilatorassociated pneumonia (HAP/VAP) occur in 5 to $>20$ cases per 1000 hospital admissions and 2-16 episodes per 1000 ventilator days, respectively [1]. Methicillin-sensitive and methicillinresistant Staphylococcus aureus (S. aureus; MSSA and MRSA) are important disease-causing pathogens in HAP/VAP [2, 3]. In 2016, the Infectious Diseases Society of America (IDSA) and American Thoracic Society (ATS) recommended vancomycin or linezolid in patients with HAP/VAP when empiric coverage of MRSA is indicated [3], despite some evidence of reduced susceptibility to vancomycin in MRSA and MSSA isolates [4]. Rising MRSA vancomycin minimum inhibitory concentration (MIC) values are not universal, and vancomycin-intermediate $S$. aureus (VISA) remains uncommon [3]. However, S. aureus strains with vancomycin MIC 1-2 $\mu \mathrm{g} / \mathrm{mL}$-considered vancomycin-susceptible-may harbor vancomycin-intermediate subpopulations, and heterogeneous VISA (hVISA) prevalence among $S$. aureus isolates increased significantly from $0.4 \%$ in 2009 to $1.2 \%$ in 2011 in the US [5]. Furthermore, MRSA infections with organisms with vancomycin MIC $\geq 1.5 \mu \mathrm{g} / \mathrm{mL}$ (excluding documented hVISA) are significantly associated with treatment failure [4]. Linezolid is not bactericidal against staphylococci and is not suitable for all patients due to drug interactions and hematologic effects [6]. Ceftobiprole is approved in the UK and other countries for treatment of HAP but is not indicated for VAP and not available in the US $[7,8]$. Alternative treatment options are needed for patients with HAP/VAP caused by $S$. aureus with high vancomycin MICs and patients unable to tolerate vancomycin or linezolid.

Telavancin is a rapidly acting bactericidal lipoglycopeptide antibiotic with a dual mechanism of action, including inhibition of bacterial cell wall biosynthesis and disruption of cell membrane function [9]. In the US, telavancin is approved in adults for treatment of complicated skin and skin structure infections due to susceptible Gram-positive pathogens. In addition, telavancin is approved for hospital-acquired and ventilator-associated bacterial pneumonia (HABP/VABP) when alternative treatments are not suitable [10]. In a post hoc analysis, telavancin demonstrated comparable efficacy to vancomycin in a limited number of patients with HABP/VABP with concurrent $S$. aureus bacteremia [11]. Telavancin provides clinical outcomes that are noninferior to vancomycin in treatment of patients with HABP due to both MSSA and MRSA [2]. This post hoc analysis of the Assessment of Telavancin for Treatment of Hospital-Acquired Pneumonia (ATTAIN) trials [2] assesses a subset of microbiologically evaluable patients with hospital-acquired baseline monomicrobial $S$. aureus respiratory infections with vancomycin $\mathrm{MIC} \geq 1.0 \mu \mathrm{g} / \mathrm{mL}$.

\section{METHODS}

Methods and results from the identical, randomized, double-blind, comparator-controlled, parallel-group phase 3 ATTAIN trials (NCT00107952 and NCT00124020) were reported previously [2]. Briefly, adult patients who developed pneumonia after $48 \mathrm{~h}$ of inpatient care or $<7$ days after discharge were eligible; patients who received other potentially effective therapy for $>24 \mathrm{~h}$ before randomization had only Gram-negative bacteria on Gram stain or culture, or had other pulmonary disease precluding evaluation of therapeutic response were excluded [2]. Patients were randomized to receive intravenous telavancin $10 \mathrm{mg} / \mathrm{kg}$ every $24 \mathrm{~h}$ or vancomycin $1 \mathrm{~g}$ intravenously every $12 \mathrm{~h}$ for 7-21 days; the vancomycin regimen could be monitored and adjusted according to the institutional policy at each site but had to be performed such that blinding was not 
compromised [2]. All procedures performed in studies involving human participants were in accordance with the ethical standards of the institutional and/or national research committee and with the 1964 Helsinki declaration and its later amendments or comparable ethical standards. Informed consent was obtained from all individual participants included in the study.

Clinical assessments were performed at baseline and daily throughout study treatment, at end of therapy, and at follow-up/test-of-cure visits [2]. Modified Acute Physiology and Chronic Health Evaluation (APACHE II) was performed at baseline; missing score components were imputed as 0 . Efficacy endpoints were proportions of clinical cure, defined as lack of progression or improvement in radiographic findings at end of treatment and resolution of signs and symptoms of pneumonia at follow-up or test-of-cure visits [2], and all-cause 28-day mortality, measured as Kaplan-Meier survival estimate at day 28 based on reported deaths. Safety was assessed from adverse events (AEs); renal safety was determined by rate of decline in renal function, defined as creatinine clearance $(\mathrm{CrCl})$ shift from baseline by two or more categories $(<30,30-50,>50-80$, and $>80 \mathrm{~mL} / \mathrm{min})$ during therapy [12]. Creatinine clearance was calculated by Cockcroft-Gault using the smaller of ideal or actual body weight.

This post hoc subgroup analysis assessed microbiologically evaluable patients from ATTAIN with monomicrobial respiratory infections caused by $S$. aureus with vancomycin MIC $\geq 1.0 \mu \mathrm{g} / \mathrm{mL}$. Vancomycin MIC was determined from broth microdilution methods; identification of hVISA was not performed prospectively. Patients who were protocol-adherent or died from HAP on or after study day 3 and had a Gram-positive respiratory pathogen recovered from baseline respiratory specimens or blood cultures were considered microbiologically evaluable [2] and included. Efficacy and safety analyses included all randomized microbiologically evaluable patients receiving $\geq 1$ dose of study medication. Subgroup analyses of clinical cure were performed by patient age ( $\geq 65$ years vs. $<65$ years), VAP diagnosis, APACHE II score $(\geq 20$ vs. $<20$ ), and pathogen (MSSA vs. MRSA).
Differences in proportion were calculated using a 95\% Wald confidence interval (CI) adjusted via the Agresti-Caffo method. No formal hypothesis testing was performed. Treatmentemergent AEs (TEAEs) were summarized by preferred term and system organ class.

\section{RESULTS}

Of 1503 patients treated in ATTAIN, 194 microbiologically evaluable patients had monomicrobial respiratory $S$. aureus infections with vancomycin MIC $\geq 1.0 \mu \mathrm{g} / \mathrm{mL} ; 89$ patients were treated with telavancin, and 105 with vancomycin. Demographics and baseline characteristics were comparable in telavancin- and vancomycin-treated patients (Table 1). The majority of patients were $\geq 65$ years of age, male, and white (Table 1). At baseline, $24.2 \%$ of patients had VAP, 76.8\% had MRSA, and the proportion of patients with MRSA was numerically lower among those treated with telavancin versus vancomycin (Table 1). The most common comorbidities among telavancin- and vancomycin-treated patients were hypertension $(62.9 \%)$, anemia (37.6\%), diabetes mellitus $(35.6 \%)$, chronic obstructive airway disease (26.8\%), atrial fibrillation $(24.2 \%)$, and congestive cardiac failure $(18.6 \%)$; proportions of patients with renal comorbidities were comparable between treatment arms (Table 1).

The overall clinical cure rate for telavancin treatment was 76/89 (85.4\%) versus 78/105 (74.3\%) for vancomycin treatment [treatment difference (95\% CI), 11.1\% (- 0.002\%, 22.2\%)]. Clinical cure rates were numerically greater for telavancin relative to vancomycin treatment in patients $\geq 65$ years of age $[40 / 49(81.6 \%)$ vs. $45 / 68$ (66.2\%); treatment difference $(95 \% \mathrm{CI})$, $15.5 \%(-0.9 \%, 30.2 \%)]$, although similar in patients aged $<65$ years $[36 / 40(90.0 \%)$ and $33 / 37$ (89.2\%); treatment difference (95\% CI), $0.8 \%$ (-13.4\%, 15.3\%)] (Fig. 1). Telavancin treatment also produced numerically greater clinical cure rates relative to vancomycin in patients with VAP $[24 / 26(92.3 \%)$ vs. $10 / 21$ (47.6\%); treatment difference (95\% CI), $44.7 \%$ $(18.1 \%, 64.9 \%)]$, but similar cure rates in patients without VAP [52/63 (82.5\%) and 68/84 
Table 1 Baseline demographics of microbiologically evaluable patients with monomicrobial Staphylococcus aureus infection with vancomycin minimum inhibitory concentration $\geq 1.0 \mu \mathrm{g} / \mathrm{mL}$

\begin{tabular}{|c|c|c|c|c|c|}
\hline \multicolumn{3}{|c|}{$\begin{array}{l}\text { aureus infection with vancomycin minimum inhibitory } \\
\text { concentration } \geq 1.0 \mu \mathrm{g} / \mathrm{mL}\end{array}$} & \multicolumn{2}{|c|}{$\begin{array}{ll}\text { Characteristic } & \text { Telavancin } \\
& (n=89) \\
\end{array}$} & \multirow{2}{*}{$\begin{array}{c}\begin{array}{c}\text { Vancomycin } \\
(n=105)\end{array} \\
\begin{array}{c}63.6(40.7 \\
91.7)\end{array}\end{array}$} \\
\hline Characteristic & $\begin{array}{l}\text { Telavancin } \\
(n=89)\end{array}$ & $\begin{array}{l}\text { Vancomycin } \\
(n=105)\end{array}$ & Median (IQR) & $68.5(43.0,118.5)$ & \\
\hline Age (years) & & & VAP, $n(\%)$ & & \\
\hline Mean (SD) & $61.7(18.6)$ & $67.0(15.4)$ & Yes & $26(29.2)$ & $21(20.0)$ \\
\hline Median (IQR) & $67.0(50.0,75.0)$ & $\begin{array}{l}72.0(60.0 \\
77.0)\end{array}$ & $\begin{array}{l}\text { No } \\
\text { MRSA, } n(\%)\end{array}$ & $63(70.8)$ & $84(80.0)$ \\
\hline Age distribution, $n$ (\%) & & & Yes & $61(68.5)$ & $88(83.8)$ \\
\hline$<65$ years & $40(44.9)$ & $37(35.2)$ & No & $28(31.5)$ & $17(16.2)$ \\
\hline$\geq 65$ years & $49(55.1)$ & $68(64.8)$ & MSSA, $n(\%)$ & & \\
\hline Sex, $n(\%)$ & & & Yes & $28(31.5)$ & $17(16.2)$ \\
\hline Male & $47(52.8)$ & $61(58.1)$ & No & $61(68.5)$ & $88(83.8)$ \\
\hline Female & $42(47.2)$ & $44(41.9)$ & Common comorbidities & $(\geq 20 \%), n(\%)$ & \\
\hline Ethnicity, $n$ (\%) & & & Hypertension & $55(61.8)$ & $67(63.8)$ \\
\hline Hispanic or latino & $20(22.5)$ & $21(20.0)$ & Anemia & $39(43.8)$ & $34(32.4)$ \\
\hline Not hispanic or & $69(77.5)$ & $84(80.0)$ & Diabetes mellitus & $35(39.3)$ & $34(32.4)$ \\
\hline Idting & & & Atrial fibrillation & $22(24.7)$ & $25(23.8)$ \\
\hline $\begin{array}{l}\text { American Indian or } \\
\text { Alaska Native }\end{array}$ & $5(5.6)$ & $3(2.9)$ & $\begin{array}{l}\text { Cardiac failure, } \\
\text { congestive }\end{array}$ & $22(24.7)$ & $14(13.3)$ \\
\hline Asian & $17(19.1)$ & $20(19.0)$ & $\begin{array}{l}\text { Chronic obstructive } \\
\text { airways disease }\end{array}$ & $21(23.6)$ & $31(29.5)$ \\
\hline $\begin{array}{l}\text { Black or African } \\
\text { American }\end{array}$ & $3(3.4)$ & $4(3.8)$ & Renal comorbidities & & \\
\hline White & $64(71.9)$ & $78(74.3)$ & $\begin{array}{l}\text { Renal failure, acute } \\
\text { Renal failure, chronic }\end{array}$ & $\begin{array}{l}9(10.1) \\
9(10.1)\end{array}$ & $\begin{array}{l}12(11.4) \\
9(8.6)\end{array}$ \\
\hline Mean (SD) & $26.2(5.84)$ & $25.5(6.03)$ & $\begin{array}{l}\text { Renal insufficiency } \\
\text { Renal impairment }\end{array}$ & $\begin{array}{l}4(4.5) \\
1(1.1)\end{array}$ & $5(4.8)$ \\
\hline Median (IQR) & $25.4(22.2,29.1)$ & $\begin{array}{l}23.8(21.6 \\
28.3)\end{array}$ & $\begin{array}{l}\text { Blood creatinine } \\
\text { increased }\end{array}$ & $1(1.1)$ & 0 \\
\hline
\end{tabular}

Table 1 continued

As treatment allocation was randomized, no statistical comparison of baseline characteristics was performed APACHE II Acute Physiology and Chronic Health Evaluation II, $B M I$ body mass index, $\mathrm{CrCl}$ creatinine clearance, $I Q R$ interquartile range, $M R S A$ methicillin-resistant Staphylococcus aureus, MSSA methicillin-sensitive Staphylococcus aureus, $S D$ standard deviation, VAP ventilatoracquired pneumonia 


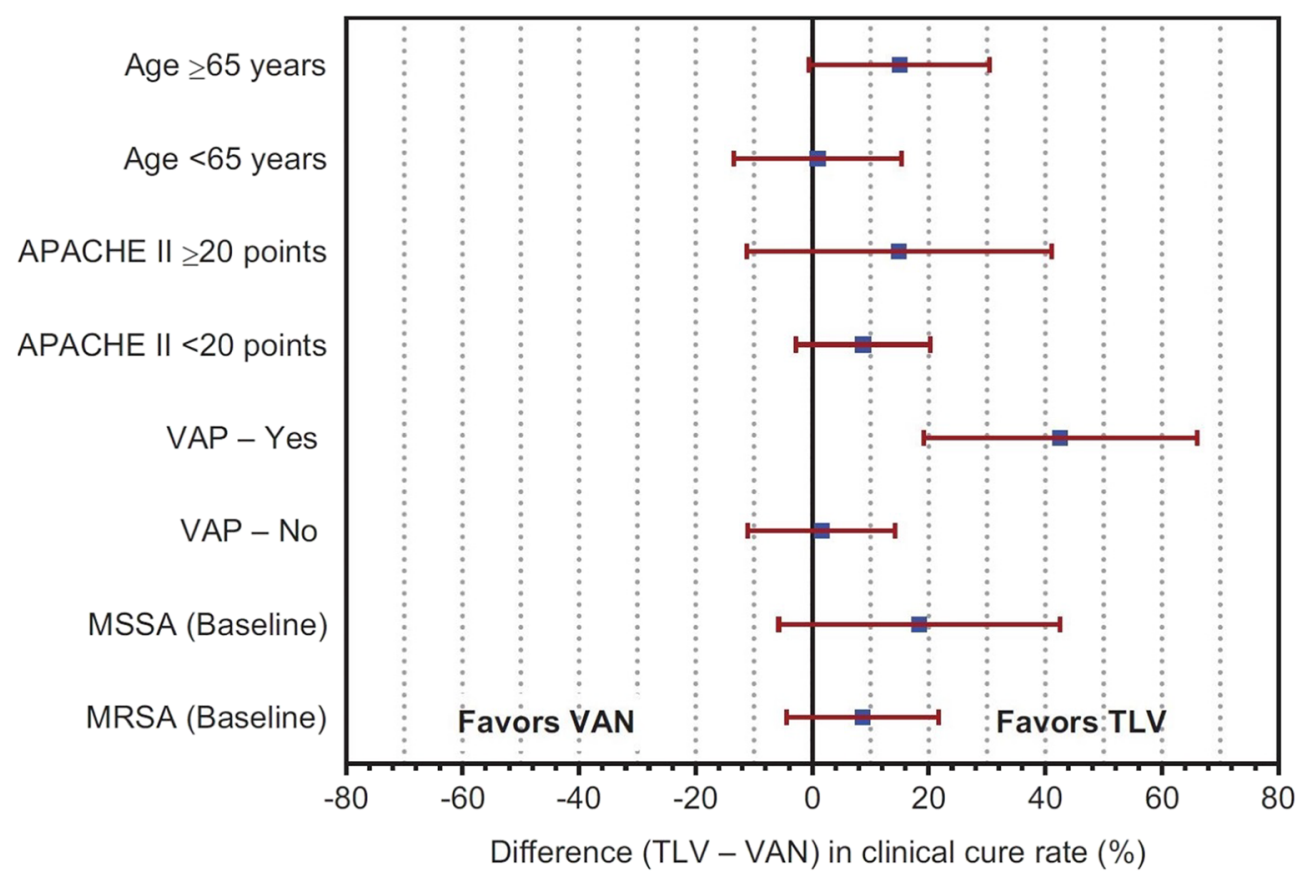

Fig. 1 Difference (telavancin-vancomycin) in clinical cure rates at test of cure with associated 95\% confidence intervals in microbiologically evaluable patients. APACHE II Acute Physiology and Chronic Health Evaluation II,
MRSA methicillin-resistant Staphylococcus aureus, MSSA methicillin-sensitive Staphylococcus aureus, TLV telavancin, $V A N$ vancomycin, $V A P$ ventilator-associated pneumonia

vancomycin 15/105 (14.3\%)], hypokalemia [telavancin 4/89 (4.5\%); vancomycin 14/105 (13.3\%)], and decubitus ulcer [telavancin 5/89 (5.6\%); vancomycin, 13/105 (12.4\%)]. A total of 7 (7.9\%) patients receiving telavancin and 6 patients $(5.7 \%)$ receiving vancomycin had renal function decline by a shift from baseline of $\geq 2$ $\mathrm{CrCl}$ categories. Over $90 \%$ of the patients (181/ 194) had no shift in renal function.

\section{DISCUSSION}

This analysis assessed the efficacy and safety of telavancin versus vancomycin in microbiologically evaluable ATTAIN patients with monomicrobial $S$. aureus respiratory infection. Clinical cure and 28-day mortality rates were numerically favorable in patients treated with telavancin versus vancomycin. Clinical cure rates were numerically greater in elderly $(\geq 65$ years of age) patients; patients with VAP; and, to a lesser degree, patients with APACHE II score $\geq 20$ treated with telavancin relative to telavancin 10/89 (11.2\%); vancomycin 19/105 (18.1\%)], anemia [telavancin 10/89 (11.2\%); 
vancomycin. Changes in renal function and incidence and types of AEs were comparable between patients receiving telavancin and vancomycin.

Despite concerns about vancomycin MIC and treatment failure [4], 2016 IDSA/ATS treatment guidelines-based on seven randomized trials including ATTAIN-recommend vancomycin or linezolid for empiric coverage of MRSA in patients with HAP/VAP [3]. Clinical outcomes in ATTAIN were comparable for telavancin or vancomycin treatment with the exception of a trend toward greater all-cause mortality in patients with $\mathrm{CrCl}<30 \mathrm{~mL} / \mathrm{min}$ treated with telavancin versus vancomycin $[2,13]$. In this post hoc analysis of ATTAIN, telavancin had at least comparable efficacy relative to vancomycin in patients with monomicrobial $S$. aureus HAP/VAP caused by both MSSA and MRSA with vancomycin MIC $\geq 1 \mu \mathrm{g} / \mathrm{mL}$; clinical cure rates for patients treated with telavancin versus vancomycin were similar to those for all patients with monomicrobial $S$. aureus in ATTAIN [2]. The small number of patients prevented meaningful subgroup analysis of patients with reduced renal function. Telavancin could potentially be useful for treatment coverage of MRSA in patients with HAP/VAP acquired in facilities with organisms with high vancomycin MICs.

Vancomycin dosing in this study was $1 \mathrm{~g}$ every $12 \mathrm{~h}$, but could be monitored and adjusted according to the institutional policy per site, and dosing to trough levels was allowed. In the ATTAIN studies, $66 \%$ of patients had mean vancomycin trough concentrations $\geq 10 \mu \mathrm{g} /$ $\mathrm{mL}$. Although the 2016 IDSA guidelines recommend a target trough concentration of $15-20 \mu \mathrm{g} / \mathrm{mL}$ for treatment of HAP with risk of MRSA [2, 3], another post hoc analysis revealed that ATTAIN patients with vancomycin trough levels $\geq 15 \mu \mathrm{g} / \mathrm{mL}$ had a higher incidence of renal AEs without improvement in clinical cure rate relative to those with lower trough levels [14]. Appropriate vancomycin dosing for optimized efficacy and safety remains a challenge. The study is limited by its post hoc nature, small patient numbers-particularly in subgroup analyses-and lack of significance testing. However, clinical cure rates were comparable or greater in patients with HAP/VAP caused by $S$. aureus with vancomycin MIC $\geq 1 \mu \mathrm{g} / \mathrm{mL}$ treated with telavancin relative to vancomycin. Patient age, VAP diagnosis, and baseline APACHE II score may inform decisions regarding using telavancin versus vancomycin in this population, as the numerically favorable clinical cure rates for elderly patients, patients with VAP, and patients with baseline APACHE II score $\geq 20$ treated with telavancin versus vancomycin suggest a benefit of telavancin treatment in such patients. Dedicated studies with larger populations of patients meeting these criteria could clarify any possible advantages of telavancin relative to other treatment options.

\section{CONCLUSIONS}

In settings where organisms with vancomycin MIC $\geq 1 \mu \mathrm{g} / \mathrm{mL}$ are prevalent, telavancin is an alternative to vancomycin for empiric or specific coverage of MRSA in patients with HAP/VAP. The potential benefits of telavancin versus vancomycin must be balanced with possible increased risks for decline in renal function and trends for increased mortality in patients with pre-existing renal impairment.

\section{ACKNOWLEDGMENTS}

The authors extend our thanks to the patients and their families for participation in ATTAIN.

Funding. The analysis and publication were funded by Theravance Biopharma R\&D, Inc., South San Francisco, CA, USA. All authors had full access to all of the data in this study and take complete responsibility for the integrity of the data and accuracy of the data analysis.

Medical Writing, Editorial, and Other Assistance. Medical writing support was provided by Judith M. Phillips, DVM, PhD, of AlphaBioCom, LLC, and funded by Theravance Biopharma R\&D, Inc.

Authorship. All named authors meet the International Committee of Medical Journal 
Editors (ICMJE) criteria for authorship for this article, take responsibility for the integrity of the work as a whole, and have given their approval for this version to be published.

Prior Presentation. Parts of this analysis were presented at the American Thoracic Society Conference, San Francisco, CA, May 13-18, 2016.

Disclosures. Steven L. Barriere is a former employee of Theravance Biopharma US, Inc. Steven L. Barriere is now an Independent Consultant, San Francisco, CA, USA. Chris N. Barnes is a former employee of Theravance Biopharma US, Inc. Chris N. Barnes' current affiliation is Spruce Biosciences, San Francisco, CA, USA. Bibiana Castaneda-Ruiz is a former employee of Theravance Biopharma US, Inc. Bibiana Castaneda-Ruiz is now an Independent Consultant, San Francisco, CA, USA. Michael S. Niederman has served as a consultant for Pfizer; Merck; Bayer; Theravance Biopharma R\&D, Inc.; Paratek; and Shionogi; and has received research support from Bayer and Pfizer. Patrick C. Lee has served as a consultant for Smiths Medical and received honoraria from Wyeth, King Pharmaceutical, and Adolor Corporation.

Compliance with Ethics Guidelines. All procedures performed in studies involving human participants were in accordance with the ethical standards of the institutional and/or national research committee and with the 1964 Helsinki declaration and its later amendments or comparable ethical standards. Informed consent was obtained from all individual participants included in the study.

Data Availability. Theravance Biopharma, Inc. (and its affiliates), will not be sharing individual de-identified participant data or other relevant study documents.

Open Access. This article is distributed under the terms of the Creative Commons Attribution-NonCommercial 4.0 International License (http://creativecommons.org/licenses/ by-nc/4.0/), which permits any noncommercial use, distribution, and reproduction in any medium, provided you give appropriate credit to the original author(s) and the source, provide a link to the Creative Commons license, and indicate if changes were made.

\section{REFERENCES}

1. Barbier F, Andremont A, Wolff M, Bouadma L. Hospital-acquired pneumonia and ventilator-associated pneumonia: recent advances in epidemiology and management. Curr Opin Pulm Med. 2013;19(3):216-28

2. Rubinstein E, Lalani T, Corey GR, et al. Telavancin vs vancomycin for hospital-acquired pneumonia due to gram-positive pathogens. Clin Infect Dis. 2011;52(1):31-40.

3. Kalil AC, Metersky ML, Klompas M, et al. Management of adults with hospital-acquired and ventilator-associated pneumonia: 2016 clinical practice guidelines by the Infectious Diseases Society of America and the American Thoracic Society. Clin Infect Dis. 2016;63(5):e61-111.

4. van Hal SJ, Lodise TP, Paterson DL. The clinical significance of vancomycin minimum inhibitory concentration in Staphylococcus aureus infections: a systematic review and meta-analysis. Clin Infect Dis. 2012;54(6):755-71.

5. Richter SS, Diekema DJ, Heilmann KP, et al. Activities of vancomycin, ceftaroline, and mupirocin against Staphylococcus aureus isolates collected in a 2011 national surveillance study in the United States. Antimicrob Agents Chemother. 2014;58(2):740-5.

6. ZYVOX $^{\circledR}$ (linezolid) injection, tablets and oral suspension. Full prescribing information. Pharmacia \& Upjohn, New York. 2018.

7. Zevtera (ceftobiprole) $500 \mathrm{mg}$ powder for concentrate for solution for infusion. Summary of product characteristics. Correvio, Puteaux, France. 2018.

8. Basilea reports clinical phase 3 study start with antibiotic ceftobiprole in skin infections under BARDA contract. Basel, Switzerland: Basilea Pharmaceutica, Ltd.; February 23, 2018. https://www. basilea.com/fileadmin/user_upload/pressreleases/ 1386445-en-836557.pdf. Accessed 20 May 2019.

9. Higgins DL, Chang R, Debabov DV, et al. Telavancin, a multifunctional lipoglycopeptide, disrupts both cell wall synthesis and cell membrane integrity in methicillin-resistant Staphylococcus 
aureus. Antimicrob Agents Chemother. 2005;49(3):1127-34.

10. VIBATIV $^{\circledR}$ (telavancin) for injection, for intravenous use. Full Prescribing Information. Theravance Biopharma US, South San Francisco. 2016.

11. Wilson SE, Graham DR, Wang W, Bruss JB, Castaneda-Ruiz B. Telavancin in the treatment of concurrent Staphylococcus aureus bacteremia: a retrospective analysis of ATLAS and ATTAIN studies. Infect Dis Ther. 2017;6(3):413-22.

12. Nogid B, Lacy MK, Jacobs M, Bruss J, Dwyer J. Time course and extent of renal function changes in patients receiving treatment for Staphylococcal pneumonias: an analysis comparing telavancin and vancomycin from the ATTAIN trials. Pharmacotherapy. 2018;38(10):990-8.

13. Corey GR, Kollef MH, Shorr AF, et al. Telavancin for hospital-acquired pneumonia: clinical response and 28-day survival. Antimicrob Agents Chemother. 2014;58(4):2030-7.

14. Barriere SL, Stryjewski ME, Corey GR, Genter FC, Rubinstein E. Effect of vancomycin serum trough levels on outcomes in patients with nosocomial pneumonia due to Staphylococcus aureus: a retrospective, post hoc, subgroup analysis of the Phase 3 ATTAIN studies. BMC Infect Dis. 2014;14:183. 